\title{
Suppression of the hypothalamic-pituitary- thyroid axis is associated with the severity of prognosis in hospitalized patients with COVID-19
}

Juan Zheng ${ }^{1,2+}$, Zhenhai Cui ${ }^{1,2+}$, Ningjie Shi ${ }^{1,2+}$, Shenghua Tian ${ }^{1,2}$, Ting Chen ${ }^{1,2}$, Xueyu Zhong ${ }^{1,2}$, Kangli Qiu ${ }^{1,2}$, Jiaoyue Zhang ${ }^{1,2}$, Tianshu Zeng ${ }^{1,2^{*}}$, Lulu Chen ${ }^{1,2^{*}}$ and Huiqing Li $\mathrm{Li}^{1,2^{*}}$

\begin{abstract}
Background: The outbreak of severe acute respiratory syndrome novel coronavirus 2 (SARS-CoV-2) has spread rapidly worldwide. SARS-CoV-2 has been found to cause multiple organ damage; however, little attention has been paid to the damage to the endocrine system caused by this virus, and the subsequent impact on prognosis. This may be the first research on the hypothalamic-pituitary-thyroid (HPT) axis and prognosis in coronavirus disease 2019 (COVID-19).

Methods: In this retrospective observational study, 235 patients were admitted to the hospital with laboratoryconfirmed SARS-CoV-2 infection from 22 January to 17 March 2020. Clinical characteristics, laboratory findings, and treatments were obtained from electronic medical records with standard data collection forms and compared among patients with different thyroid function status.

Results: Among 235 patients, 17 (7.23\%) had subclinical hypothyroidism, 11 (4.68\%) severe non-thyroidal illness syndrome (NTIS), and 23 (9.79\%) mild to moderate NTIS. Composite endpoint events of each group, including mortality, admission to the ICU, and using IMV were observed. Compared with normal thyroid function, the hazard ratios (HRs) of composite endpoint events for mild to moderate NTIS, severe NTIS, subclinical hypothyroidism were 27.3 (95\% confidence interval [Cl] 7.07-105.7), 23.1 (95\% Cl 5.75-92.8), and 4.04 (95\% Cl 0.69-23.8) respectively. The multivariate-adjusted HRs for acute cardiac injury among patients with NTF, subclinical hypothyroidism, severe NTIS, and mild to moderate NTIS were 1.00, 1.68 (95\% Cl 0.56-5.05), 4.68 (95\% Cl 1.76-12.4), and 2.63 (95\% Cl 1.09-6.36) respectively.
\end{abstract}

\footnotetext{
*Correspondence: tszeng@126.com; cheria_chen@126.com;

Ihqing5@126.com

†Juan Zheng, Zhenhai Cui and Ningjie Shi contributed equally to this work

${ }^{1}$ Department of Endocrinology, Union Hospital, Tongji Medical College, Huazhong University of Science and Technology, Wuhan 430022, China

Full list of author information is available at the end of the article
}

(c) The Author(s). 2021 Open Access This article is licensed under a Creative Commons Attribution 4.0 International License, which permits use, sharing, adaptation, distribution and reproduction in any medium or format, as long as you give appropriate credit to the original author(s) and the source, provide a link to the Creative Commons licence, and indicate if changes were made. The images or other third party material in this article are included in the article's Creative Commons licence, unless indicated otherwise in a credit line to the material. If material is not included in the article's Creative Commons licence and your intended use is not permitted by statutory regulation or exceeds the permitted use, you will need to obtain permission directly from the copyright holder. To view a copy of this licence, visit http://creativecommons.org/licenses/by/4.0/. The Creative Commons Public Domain Dedication waiver (http://creativecommons.org/publicdomain/zero/1.0/) applies to the data made available in this article, unless otherwise stated in a credit line to the data. 
Conclusions: Our study shows that the suppression of the HPT axis could be a common complication in COVID-19 patients and an indicator of the severity of prognosis. Among the three different types of thyroid dysfunction with COVID-19, mild to moderate NTIS and severe NTIS have a higher risk of severe outcomes compared with subclinical hypothyroidism.

Keywords: Coronavirus disease 2019, Hypothalamic-pituitary-thyroid axis, Non-thyroidal illness syndrome, Subclinical hypothyroidism

\section{Background}

Coronavirus disease 2019 (COVID-19), a new global pandemic that first emerged in December 2019, is caused by severe acute respiratory syndrome coronavirus 2 (SARSCoV-2). Due to its abrupt outbreak, rapid spread, and striking mortality, COVID-19 has drawn wide attention from various countries and regions, with more than 224 million confirmed cases and more than 4.6 million deaths as of September 12, 2021 [1]. One of the reasons for this catastrophic outcome is that SARS-CoV-2 attacks the body's major organs through angiotensin-converting enzyme 2 (ACE2), a main viral entry receptor that is widely distributed in the lungs, heart, liver, and kidney, and causes damage to multiple organs [2]. However, little attention has been paid to the damage to the endocrine system caused by this virus, and the subsequent impact on prognosis.

In a previous study on endocrine dysfunction caused by severe acute respiratory syndrome (SARS) [3], the hypothalamicpituitary-adrenal (HPA) and hypothalamic-pituitary-thyroid (HPT) axis were candidate targets for SARS-CoV. This study observing 61 SARS survivors found that $6.7 \%$ of patients had hypothyroidism including central hypothyroidism and primary hypothyroidism. Severe airway obstruction, hypoxemia, systemic inflammation, and glucocorticoid use may easily develop into subclinical hypothyroidism, overt hypothyroidism, and non-thyroid illness syndrome [4]. Non-thyroid illness syndrome (NTIS) was defined as the decreased concentrations of plasma tri-iodothyronine, low thyroxine, and normal range or slightly decreased concentration of thyroid-stimulating hormone [5]. Non-thyroid illness syndrome (NTIS) is common in patients with chronic obstructive pulmonary disease (COPD) regardless of whether the disease is stable or aggravated [6]. Several systemic inflammatory cytokines, such as IL-6, IL-1 and TNF- $\alpha$, which are observed at elevated levels among patients with COPD, inhibit TSH synthesis or secretion $[4,6]$. SARS-CoV-2 could induce reversible thyroid dysfunction, and the low T3 syndrome could be associated with the severity of COVID-19 [7]. These studies have shown that the HPT axis is altered in patients with SARS or COPD. In clinical experiences, we found that some patients with COVID-19 had suppressed thyroid function, suggesting that the HPT axis may be affected by SARS-CoV-2. However, little is known about the relationship between COVID-19 and the HPT axis.
In the present study, according to the results of thyroid function tests, patients were divided into four categories: normal thyroid function (NTF), subclinical hypothyroidism, mild to moderate NTIS, and severe NTIS. We then compared the clinical characteristics, laboratory findings, medication use, complications, and composite endpoint events of each group. Therefore, the aim of this study is to evaluate whether changes in the HPT axis are associated with the severity of prognosis of COVID-19 and to explore the risk factors associated with these changes.

\section{Methods}

\section{Study design and participants}

This is a retrospective study conducted in the West Campus unit of Wuhan Union Hospital. A total of 300 COVID-19 inpatients were admitted and received treatment between January 25, 2020 and March 17, 2020. These patients were diagnosed for COVID-19 based on the detection SARS-CoV-2, following the interim guidelines outlined by the World Health Organization (WHO) [8]. Prior to the enrollment of these inpatients in the study, they were subjected to an investigation of their thyroid function. Off these, a total of 235 patients were included in the analysis and remaining 65 inpatients were excluded from the study for either of the following reasons: (i) 13 patients had incomplete medical history/treatment history, (ii) 16 patients had preexisting thyroid dysfunction, (iii) 5 patients had hyperthyroidism, (iv) 13 female patients were found to be pregnant, (v) 7 patients had end-stage of chronic organ dysfunction, (vi) the 11 patients were administered dopamine treatment before thyroid function test.

The current study was reviewed and approved by the ethics committee of Tongji Medical College, Huazhong University of Science and Technology, Wuhan, P. R China. Written informed consent was waived by the ethics committee of the designated hospital under the criteria of emerging infectious diseases. The clinical data of enrolled participants were anonymously treated and analyzed. As of April 4, 2020, among 235 inpatients included in the study, 6.8\% (16/235) died and 93.2\% (219/ 235) recovered. 


\section{Data collection}

The data was collected by a standardized electronic medical record data collection form. A well-trained team of doctors and researchers from Wuhan Union Hospital independently input and cross-checked the data into a computer database. Two researchers (C.Z., T.S.) in our team independently reviewed the clinical data of all laboratoryconfirmed patients infected with SARS-CoV-2.

Basic information (age, sex, and shared medical history) was collected for each patient (addendum). Within three days after admission to the hospital, laboratory blood parameters including standard blood count (absolute white blood cells and lymphocytes, hemoglobin concentration, platelet count, arterial blood gas analysis, supply, and oxygen partial pressure $[\mathrm{PaO} 2]$ ), blood biochemistry (including liver and kidney function, creatine kinase, fasting plasma glucose, HbA1c, lactate dehydrogenase and electrolytes), coagulation, procalcitonin, c-reactive protein (CRP), erythrocyte sedimentation rate (ESR), myocardial enzyme spectrum, and thyroid function (free triiodothyronine, free thyroxine, and thyroid-stimulating hormone) were measured. No enrolled patients received dopamine treatment before thyroid function test and received thyroid hormone replacement therapy in hospital. Other data included medical imaging, treatment regimens (antiviral and antimicrobial agents), systemic corticosteroids, immunoglobulin G, respiratory support (such as nasal tubes, mask, high-flow nasal intubation, noninvasive and invasive mechanical ventilation), and prognosis (discharge or death).

\section{Classification of thyroid function abnormality}

Patients were classified into four categories based on the reference range of thyroid function index in our hospital after admission: normal thyroid function (NTF) group, subclinical hypothyroidism group (FT3 within 2.63-5.7 $\mathrm{pmol} / \mathrm{L}$ and FT4 within $9-19.18 \mathrm{pmol} / \mathrm{L}$ and $\mathrm{TSH}>4.94$ $\mu \mathrm{IU} / \mathrm{ml}$ ) [9], severe NTIS group (FT3 $<2.63 \mathrm{pmol} / \mathrm{L}$ and $\mathrm{TSH}<0.35 \mu \mathrm{IU} / \mathrm{ml} ; \quad$ FT $4<9 \mathrm{pmol} / \mathrm{L}$ and $\mathrm{FT} 3<2.63$ $\mathrm{pmol} / \mathrm{L}$ and $\mathrm{TSH}<0.35 \mu \mathrm{IU} / \mathrm{ml} ; \mathrm{FT} 4<9 \mathrm{pmol} / \mathrm{L}$ and $\mathrm{TSH}<0.35 \mu \mathrm{IU} / \mathrm{ml}$ ) [10], and mild to moderate NTIS group $(\mathrm{FT} 3<2.63 \mathrm{pmol} / \mathrm{L}$ or $\mathrm{FT} 4<9 \mathrm{pmol} / \mathrm{L}$ and $\mathrm{TSH}$ within $0.35-4.94 \mu \mathrm{IU} / \mathrm{ml}$ ) [10].

\section{Study outcomes}

The primary component endpoint events included the use of invasive mechanical ventilation (IMV), admission to the intensive care unit (ICU), or death events. The duration of follow-up time for each patient (persondays) was calculated from the first diagnosis date of COVID-19 to the index date of discharge, death of inpatients, or transfer to other hospitals. We also assessed the complications of COVID-19 in the analyses. The definitions of SARS-CoV-2-associated acute respiratory distress syndrome (ARDS) and shock referred to the interim guidance of the WHO for SARS-CoV-2 [8]. Acute cardiac injury was defined as elevated serum levels of cardiac biomarkers (such as CK-MB and hypersensitive cardiac troponin I) above the 99th percentile reference limit, or new abnormalities found in the electrocardiogram and echocardiography [11]. Acute kidney injury was diagnosed according to KDIGO clinical practice guidelines [12]. According to the CURB-65 guidelines, the severity of COVID-19 was divided into two levels: mild, severe [13]. Clotting disease was diagnosed if prothrombin time (PT) was prolonged over $3 \mathrm{~s}$ or activation of partial thromboplastin time (APTT) was prolonged over $5 \mathrm{~s}$ [14]. Hypoproteinemia was defined as blood albumin less than $30 \mathrm{~g} / \mathrm{L}$.

\section{Statistical analysis}

Differences in demographics, history of diseases, laboratory measurements, treatment and clinical outcomes among patients with the four types of thyroid function status (NTF, subclinical hypothyroidism, severe NTIS, and mild to moderate NTIS) were assessed using Pearson's chi-square or Fisher's exact test for categorical variables and the General Linear Model for continuous variables after adjustments for age and sex. Cox proportional hazards regression was used to estimate hazard ratios (HRs) of the composite endpoint of ICU, IMV, or death, and acute cardiac injury among patients with different thyroid function status. Three models were used: Model 1 adjusted for age and sex; Model 2 adjusted for age, sex, smoking, systolic blood pressure, fasting glucose, using antihypertensive medications, and using glucose-lowering drugs (36 patients were treated with insulin injection); and Model 3 adjusted for total cholesterol and using lipid-lowering agents (19 patients were treated with lipid-lowering agents). All the statistical analyses were performed with SPSS statistics V.25.0 for Windows (IBM). A two-sided $p<0.05$ was considered statistically significant.

\section{Patient and public involvement}

This was a retrospective study, no patients were directly involved in the study design, the research questions setting, or the outcome measurement. No patients were asked to advice on the interpretation or recording of the results.

\section{Results}

General characteristics of the study population at baseline are given in Table 1 . The median age of patients was 61 (interquartile range 51-69) years. Patients who had subclinical hypothyroidism, severe NTIS, and mild to moderate NTIS were slightly older, and were more likely to have histories of stroke and chronic kidney disease as compared with those in the normal group. 
Table 1 Baseline characteristics according to different thyroid function categories among patients with COVID-19

\begin{tabular}{|c|c|c|c|c|c|}
\hline & NTF & Subclinical hypothyroidism & Severe NTIS & Mild to moderate NTIS & $P$ values \\
\hline No. of participants & 184 & 17 & 11 & 23 & \\
\hline Age, years & $57.4(0.99)$ & $63.0(3.27)$ & $65.4(4.06)$ & $72.2(2.81)$ & $<0.001$ \\
\hline Men, \% & $88(47.8)$ & $6(35.3)$ & $6(54.5)$ & $12(52.2)$ & 0.696 \\
\hline \multicolumn{6}{|l|}{ History of chronic diseases, \% } \\
\hline Diabetes & $27(14.7)$ & $2(11.8)$ & $2(18.2)$ & $5(21.7)$ & 0.734 \\
\hline Hypertension & $50(27.2)$ & $6(35.3)$ & $6(54.5)$ & $11(47.8)$ & 0.063 \\
\hline Coronary heart disease & $15(8.2)$ & $1(5.9)$ & $2(18.2)$ & $4(17.4)$ & 0.247 \\
\hline Stroke & $3(1.60)$ & $0(0.00)$ & $2(18.2)$ & $4(17.4)$ & 0.001 \\
\hline Chronic pulmonary disease & $12(6.5)$ & $0(0.0)$ & $2(18.2)$ & $0(0.0)$ & 0.156 \\
\hline Chronic liver disease & $4(2.2)$ & $0(0.0)$ & $0(0.0)$ & $0(0.0)$ & 1.000 \\
\hline Chronic kidney disease & $1(0.5)$ & $0(0.0)$ & $0(0.0)$ & $3(13.0)$ & 0.011 \\
\hline Cancer & $9(4.9)$ & $1(5.9)$ & $2(18.2)$ & $2(8.7)$ & 0.168 \\
\hline \multicolumn{6}{|l|}{ Onset of symptom to, days } \\
\hline Hospital admission & $19.9(0.92)$ & $19.4(3.17)$ & $15.1(4.08)$ & $13.9(2.66)$ & 0.154 \\
\hline Confirmation of COVID-19 & $11.6(0.86)$ & $13.5(2.96)$ & $7.88(3.80)$ & $8.92(2.48)$ & 0.495 \\
\hline
\end{tabular}

Data are means (SE) and are adjusted for age and sex unless otherwise indicated percentages. Abbreviations: COVID-19 coronavirus disease 2019, NTF Normal thyroid function, NTIS Non-thyroidal illness syndrome

The laboratory parameters among COVID-19 patients are presented in Table 2. Patients with severe NTIS and patients with mild to moderate NTIS had higher mean values of CRP, white blood cell count, ESR, procalcitonin, cardiac troponin I, CKMB mass, prothrombin time, fibrinogen, lactate dehydrogenase, creatinine, blood urea nitrogen and fasting glucose than those of patients with either NTF or subclinical hypothyroidism. Patients with mild to moderate NTIS and patients with severe NTIS had lower mean values of albumin, total cholesterol and low-density lipoprotein cholesterol than those of patients with either NTF or subclinical hypothyroidism.

Table 3 shows the treatments and outcomes among COVID-19 patients with different thyroid function status. Patients with severe NTIS and mild to moderate NTIS had higher incidences of COVID-related complications, including ARDS (9.1-13.0\% vs $0.0-1.1 \%)$, acute cardiac injury (54.5-70.0\% vs $15.3-23.5 \%)$, acute kidney injury $(21.7-27.3 \%$ vs $0.0-2.7 \%)$, shock (36.4-47.8\% vs $0.0-1.6 \%)$, hypoalbuminemia $(45.5-52.2 \%$ vs $18.6-$ $23.5 \%)$, and coagulopathy (27.3-30.0\% vs $0.0-10.9 \%)$, as well as higher severe types of COVID-19 (100\% vs $75.5-$ 76.5\%) compared to patients with NTF or subclinical hypothyroidism. Patients with severe NTIS or mild to moderate NTIS were more likely to use antibiotic therapy, corticosteroid treatment, and intravenous immunoglobin treatment during hospital admission, compared to patients with NTF or subclinical hypothyroidism.

The multivariate-adjusted Cox models for the primary composite endpoint including admission to the ICU, using IMV, or death events in different thyroid function categories are shown in Table 4. Compared with normal thyroid function, mild to moderate NTIS showed the highest risk for composite endpoint (HR 27.3; 95\% confidence interval [CI] 7.07-105.7), severe NTIS had the second high risk for the composite endpoint (HR 23.1; 95\% CI 5.75-92.8), and subclinical hypothyroidism had a slightly higher risk for the composite endpoint (HR 4.04; 95\% CI 0.69-23.8), after adjusting for age, sex, smoking, systolic blood pressure, fasting glucose, using antihypertensive drugs, and using glucose-lowering drugs (Model 2). After adjustment for total cholesterol and using lipidlowering agents (Model 3), these associations had similar changes.

The multivariate-adjusted (Model 2) HRs for acute cardiac injury among patients in the normal, subclinical hypothyroidism, severe NTIS, and mild to moderate NTIS groups were, 1.00, 1.68 (95\% CI 0.56-5.05), 4.68 (95\% CI 1.76-12.4), and 2.63 (95\% CI 1.09-6.36), respectively (Table 5 ). After further adjustment for total cholesterol and using lipid-lowering agents (Model 3), these associations had similar changes.

The multivariate-adjusted (Model 2) HRs for acute cardiac injury among patients in the normal, low FT3 were, 1.00, 2.47 (95\% CI 1.13-5.37), respectively (Table 6). After adjustment for total cholesterol and using lipidlowering agents (Model 3), these associations had similar changes.

\section{Discussion}

COVID-19 is an entirely new disease caused by a new pathogen known as SARS-CoV-2, which had a high fatality rate during the initial phase of the outbreak. There are many challenges that arise in understanding the 
Table 2 Laboratory measurements according to different thyroid function categories among patients with COVID-19

\begin{tabular}{|c|c|c|c|c|c|}
\hline & NTF & Subclinical hypothyroidism & Severe NTIS & Mild to moderate NTIS & $P$ values \\
\hline No. of participants & 184 & 17 & 11 & 23 & \\
\hline White blood cell count, $\times 10^{9} / \mathrm{L}$ & $6.26(0.20)$ & $6.52(0.66)$ & $9.33(0.81)$ & $7.59(0.59)$ & 0.001 \\
\hline Neutrophil count, $\times 10^{9} / \mathrm{L}$ & $4.23(0.19)$ & $4.41(0.60)$ & $8.14(0.75)$ & $6.22(0.54)$ & $<0.001$ \\
\hline Lymphocyte count, $\times 10^{9} / \mathrm{L}$ & $1.50(0.07)$ & $1.48(0.21)$ & $0.71(0.27)$ & $0.88(0.19)$ & 0.002 \\
\hline $\mathrm{CRP}, \mathrm{mg} / \mathrm{L}$ & $17.6(2.59)$ & $7.65(8.25)$ & $82.0(10.3)$ & $67.4(7.37)$ & $<0.001$ \\
\hline Prothrombin time, s & $13.0(0.30)$ & $13.0(0.99)$ & $17.8(1.16)$ & $13.9(0.90)$ & 0.001 \\
\hline $\mathrm{ESR}, \mathrm{mm} / \mathrm{h}$ & $43.9(2.73)$ & $31.0(9.23)$ & $55.3(13.8)$ & $81.5(8.50)$ & $<0.001$ \\
\hline APTT, s & $39.7(2.26)$ & $35.1(7.61)$ & $39.8(8.91)$ & $44.3(6.88)$ & 0.843 \\
\hline D-Dimer $>0.5 \mathrm{mg} / \mathrm{L}, \%$ & $57(38.0)$ & $8(72.7)$ & $5(62.5)$ & $14(77.8)$ & 0.001 \\
\hline Fibrinogen, g & $3.79(0.08)$ & $3.29(0.27)$ & $4.72(0.32)$ & $3.88(0.25)$ & 0.009 \\
\hline Thrombin time, s & $16.4(0.71)$ & $15.4(2.40)$ & $16.5(2.81)$ & $16.3(2.17)$ & 0.982 \\
\hline $\mathrm{ALT}, \mathrm{U} / \mathrm{L}$ & $43.1(2.46)$ & $33.4(8.05)$ & $46.7(10.0)$ & $45.8(7.18)$ & 0.631 \\
\hline AST, U/L & $32.5(2.32)$ & $29.9(7.59)$ & $54.4(9.43)$ & $54.4(6.77)$ & 0.004 \\
\hline Blood urea nitrogen, $\mathrm{mmol} / \mathrm{L}$ & $5.70(0.37)$ & $7.46(1.21)$ & $11.3(1.51)$ & $7.62(1.08)$ & 0.002 \\
\hline Creatinine, $\mu \mathrm{mol} / \mathrm{L}$ & $70.0(2.00)$ & $66.2(6.53)$ & $107.2(8.12)$ & $81.6(5.83)$ & $<0.001$ \\
\hline Lactate dehydrogenase, $U / L$ & $226(9.08)$ & $216(29.1)$ & $485(36.2)$ & $387(26.0)$ & $<0.001$ \\
\hline Albumin, $\mathrm{g} / \mathrm{L}$ & $34.8(0.44)$ & $34.6(1.44)$ & $31.0(1.79)$ & $30.3(1.28)$ & 0.004 \\
\hline Total cholesterol, mmol/L & $4.63(0.09)$ & $4.97(0.29)$ & $4.04(0.33)$ & $3.95(0.24)$ & 0.012 \\
\hline Triglyceride, $\mathrm{mmol} / \mathrm{L}$ & $1.72(0.07)$ & $1.62(0.23)$ & $1.58(0.26)$ & $1.53(0.19)$ & 0.802 \\
\hline $\mathrm{HDL}-\mathrm{C}, \mathrm{mmol} / \mathrm{L}$ & $1.11(0.03)$ & $1.12(0.08)$ & $0.94(0.10)$ & $0.93(0.07)$ & 0.050 \\
\hline LDL-C mmol/L & $2.74(0.07)$ & $3.09(0.24)$ & $2.32(0.27)$ & $2.20(0.20)$ & 0.014 \\
\hline Cystatin C, mg/L & $0.93(0.13)$ & $2.44(0.42)$ & $1.32(0.52)$ & $1.12(0.37)$ & 0.008 \\
\hline Fasting glucose, $\mathrm{mmol} / \mathrm{L}$ & $6.25(0.19)$ & $6.01(0.61)$ & $8.85(0.76)$ & $8.69(0.54)$ & $<0.001$ \\
\hline Procalcitonin, ng/ml & $0.11(0.16)$ & $0.10(0.55)$ & $3.04(0.69)$ & $1.12(0.49)$ & $<0.001$ \\
\hline BNP, pg/ml & $76.8(26.7)$ & $201.2(64.2)$ & $100.9(61.3)$ & $120.4(54.2)$ & 0.349 \\
\hline Cardiac Troponin I, ng/l & $10.4(25.7)$ & $4.66(77.0)$ & $39.2(98.4)$ & $220.6(66.0)$ & 0.038 \\
\hline CKMB mass, ng/ml & $0.85(0.17)$ & $1.81(0.51)$ & $2.85(0.62)$ & $2.55(0.43)$ & $<0.001$ \\
\hline CKMB activity, U/L & $12.8(0.84)$ & $13.7(2.73)$ & $16.3(3.54)$ & $17.7(2.53)$ & 0.286 \\
\hline $\mathrm{FT} 3, \mathrm{pmol} / \mathrm{L}$ & $4.20(0.05)$ & $4.33(0.16)$ & $2.44(0.20)$ & $2.20(0.14)$ & $<0.001$ \\
\hline $\mathrm{FT} 4, \mathrm{pmol} / \mathrm{L}$ & $13.0(0.13)$ & $12.7(0.42)$ & $12.6(0.52)$ & $11.9(0.37)$ & 0.047 \\
\hline $\mathrm{THS}, \mu \mathrm{IU} / \mathrm{ml}$ & $2.08(0.08)$ & $7.06(0.27)$ & $0.13(0.33)$ & $1.26(0.24)$ & $<0.001$ \\
\hline
\end{tabular}

Data are means (SE) and are adjusted for age and sex unless otherwise indicated percentages. Abbreviations: COVID-19 coronavirus disease 2019, NTF Normal thyroid function, NTIS Non-thyroidal illness syndrome, CRP C-reactive protein, ESR Erythrocyte sedimentation rate, APTT Activation of partial thromboplastin time, $A L T$ Alanine aminotransferase, AST, Aspartate aminotransferase, HDL-C High-density lipoprotein cholesterol, LDL-C Low-density lipoprotein cholesterol, BNP B-type natriuretic peptide, FT3 Free Triiodothyronine, FT4 Free Thyroxine, TSH Thyroid-stimulating hormone

pathogenesis, clinical features, and prognostic factors of COVID-19. In the current study, we primarily investigated the relationship between different types of HPT axis abnormalities and the severity of prognosis in COVID-19. We found that several different types of thyroid dysfunctions were caused by COVID-19 illness, including mild to moderate NTIS, severe NTIS, and subclinical hypothyroidism. The alterations of myocardial injury indicators, and coagulation function index were observed in all three different thyroid function groups. Besides, all three different types of thyroid dysfunction were associated with the severity of prognosis of COVID-19. The mild to moderate NTIS group had the highest composite endpoint events, followed by the severe NTIS group. Compared with the NTF group, the subclinical hypothyroidism group had an increased rate of ICU admission and IMV usage. Moreover, we found that the risk of myocardial injury, was increased in both the severe NTIS and mild to moderate NTIS groups compared to the NTF group, and FT3 was a predictor of myocardial injury in these COVID-19 patients.

The present study found that the proportion of mild to moderate NTIS was $9.79 \%$ (23/235) in COVID-19 patients. The mild to moderate NTIS refers to changes in 
Table 3 Treatments and outcomes according to different thyroid function categories among patients with COVID-19

\begin{tabular}{|c|c|c|c|c|c|}
\hline & NTF & Subclinical hypothyroidism & Severe NTIS & Mild to moderate NTIS & $P$ values \\
\hline No. of participants & 184 & 17 & 11 & 23 & \\
\hline \multicolumn{6}{|l|}{ Treatments, \% } \\
\hline Antiviral therapy & $162(88.0)$ & $15(88.2)$ & $8(72.7)$ & $20(87.0)$ & 0.455 \\
\hline Antibiotic therapy & $104(56.5)$ & $8(47.1)$ & $9(81.8)$ & $20(87.0)$ & 0.010 \\
\hline Use of corticosteroid & $37(20.1)$ & $4(23.5)$ & $6(54.5)$ & $12(52.2)$ & 0.001 \\
\hline Intravenous immunoglobin & $18(9.8)$ & $3(17.6)$ & $5(45.5)$ & $11(47.8)$ & $<0.001$ \\
\hline Antihypertensive medicine & $56(30.4)$ & $10(58.8)$ & $4(36.4)$ & $9(39.1)$ & 0.110 \\
\hline Glucose-lowering medicine & $35(19.0)$ & $1(5.9)$ & $2(18.2)$ & $6(26.1)$ & 0.451 \\
\hline Lipid-lowering medicine & $16(8.7)$ & $0(0.0)$ & $1(9.1)$ & $2(8.7)$ & 0.686 \\
\hline Illness severity, \% & & & & & 0.005 \\
\hline Non-severe & $45(24.5)$ & $4(23.5)$ & $0(0.0)$ & $0(0.0)$ & 0.005 \\
\hline Severe & $139(75.5)$ & $13(76.5)$ & $11(100.0)$ & $23(100.0)$ & 0.005 \\
\hline \multicolumn{6}{|l|}{ Complications, \% } \\
\hline ARDS & $2(1.1)$ & $0(0.0)$ & $1(9.1)$ & $3(13.0)$ & 0.009 \\
\hline Acute cardiac injury & $27(15.3)$ & $4(23.5)$ & $7(70.0)$ & $12(54.5)$ & $<0.001$ \\
\hline Acute kidney injury & $5(2.7)$ & $0(0.0)$ & $3(27.3)$ & $5(21.7)$ & $<0.001$ \\
\hline Shock & $3(1.6)$ & $0(0.0)$ & $4(36.4)$ & $11(47.8)$ & $<0.001$ \\
\hline Hypoalbuminemia (albumin < $30 \mathrm{~g} / \mathrm{L}$ ) & $34(18.6)$ & $4(23.5)$ & $5(45.5)$ & $12(52.2)$ & 0.001 \\
\hline Coagulopathy & $19(10.9)$ & $0(0.0)$ & $3(27.3)$ & $6(30.0)$ & 0.015 \\
\hline Length of hospital stay, days & $23.4(0.99)$ & $25.5(3.23)$ & $24.8(4.02)$ & $23.1(2.89)$ & 0.917 \\
\hline
\end{tabular}

Data are means (SE) and are adjusted for age and sex unless otherwise indicated percentages. Abbreviations: COVID-19 coronavirus disease 2019, NTF Normal thyroid function, NTIS Non-thyroidal illness syndrome, ARDS Acute respiratory distress syndrome

serum thyroid hormone levels observed in critically ill patients in the absence of hypothalamic-pituitary-thyroid primary dysfunction $[15,16]$. Affected individuals had low T3, elevated rT3, and inappropriately normal TSH levels due to the changes in thyroid hormone binding, peripheral thyroid hormone uptake, and in the expression and activity of type 1 and type 3 deiodinase resulting from severe illness $[17,18]$. Inflammatory cytokines could play a role in the deiodinase expression disorder and oxidative stress caused by the production of reactive oxygen species (ROS) and may disrupt the function of deiodinase [4]. In our study, compared with the NTF group or the subclinical hypothyroidism group, the group with mild to moderate NTIS group had higher CRP, WBC count, ESR, and procalcitonin, suggesting that NTIS may be the result of severe inflammation. In addition, troponin, $\mathrm{CK}-\mathrm{MB}$ and $\mathrm{LDH}$ in the mild to moderate NTIS group were higher than those in the

Table 4 Hazard ratios of combined endpoint events according to different thyroid function categories among patients with COVID19

\begin{tabular}{|c|c|c|c|c|c|c|}
\hline & \multirow{2}{*}{$\begin{array}{l}\text { No. of } \\
\text { participants }\end{array}$} & \multirow{2}{*}{$\begin{array}{l}\text { No. } \\
\text { of } \\
\text { cases }\end{array}$} & \multirow{2}{*}{$\begin{array}{l}\text { Person- } \\
\text { days }\end{array}$} & \multicolumn{3}{|c|}{ Hazard ratios ( $95 \%$ confidence intervals) } \\
\hline & & & & Model 1 & Model 2 & Model 3 \\
\hline \multicolumn{7}{|l|}{ Combined endpoint events ${ }^{a}$} \\
\hline NTF & 184 & 5 & 5753 & 1.00 & 1.00 & 1.00 \\
\hline Subclinical hypothyroidism & 17 & 2 & 524 & $5.55(1.01-30.5)$ & $4.04(0.69-23.8)$ & $7.14(1.26-40.6)$ \\
\hline Severe NTIS & 11 & 6 & 350 & $18.8(5.05-69.9)$ & $23.1(5.75-92.8)$ & $22.1(6.09-79.9)$ \\
\hline Mild to moderate NTIS & 23 & 15 & 685 & $21.0(6.04-72.7)$ & $27.3(7.07-105.7)$ & $30.1(9.89-91.3)$ \\
\hline
\end{tabular}

Model 1 adjusted for age and sex. Model 2 adjusted for age, sex, smoking, systolic blood pressure, fasting glucose, using antihypertensive drugs, and using glucose-lowering drug. Model 3 adjusted for total cholesterol and using lipid-lowering agents. ${ }^{\mathrm{a} C o m b i n e d}$ endpoint events: The primary end point was a composite of death or using invasive mechanical ventilation or admission to Intensive care unit. Abbreviations: COVID-19 coronavirus disease 2019, NTF Normal thyroid function, NTIS Non-thyroidal illness syndrome 
Table 5 Hazard ratios of acute cardiac injury according to different thyroid function categories among patients with COVID-19

\begin{tabular}{|c|c|c|c|c|c|c|}
\hline & \multirow{2}{*}{$\begin{array}{l}\text { No of } \\
\text { participants }\end{array}$} & \multirow{2}{*}{$\begin{array}{l}\text { No. } \\
\text { of } \\
\text { cases }\end{array}$} & \multirow{2}{*}{$\begin{array}{l}\text { Person- } \\
\text { days }\end{array}$} & \multicolumn{3}{|c|}{ Hazard ratios ( $95 \%$ confidence intervals) } \\
\hline & & & & Model 1 & Model 2 & Model 3 \\
\hline \multicolumn{7}{|l|}{ Acute cardiac injury } \\
\hline NTF & 184 & 27 & 5753 & 1.00 & 1.00 & 1.00 \\
\hline Subclinical hypothyroidism & 17 & 4 & 524 & $1.68(0.58-4.86)$ & $1.68(0.56-5.05)$ & $1.97(0.67-5.78)$ \\
\hline Severe NTIS & 11 & 7 & 350 & $3.78(1.57-9.14)$ & $4.68(1.76-12.4)$ & $4.20(1.78-9.90)$ \\
\hline Mild to moderate NTIS & 23 & 12 & 685 & $2.50(1.13-5.52)$ & $2.63(1.09-6.36)$ & $3.93(1.96-7.89)$ \\
\hline
\end{tabular}

NTF and subclinical hypothyroidism groups. The proportion of D-dimer $(>0.5 \mathrm{mg} / \mathrm{L})$ that increased in the mild to moderate NTIS group was higher than in the other three groups. Thus, patients with mild to moderate NTIS had severe inflammation, myocardial injury, and coagulation abnormalities, which might explain the highest incidence of compound endpoint in patients with mild to moderate NTIS, suggesting that mild to moderate NTIS requires special attention and may be an indicator of poor prognosis.

Approximately 4.68\% (11/235) of COVID-19 patients had severe NTIS. Pathogenesis of NTIS in long-term critical illness includes suppression of hypothalamic thyrotropin-releasing hormone, accounting for persistently reduced secretion of thyroid-stimulating hormone despite low plasma thyroid hormone. In addition, existing studies have found that SARS-CoV can invade the brain tissue. In some cases distinguishing between NTIS and central hypothyroidism can be difficult, so severe NTIS may include central hypothyroidism. The global incidence of central hypothyroidism ranges from 1 in 20,000 to 1 in 80,000 in the general population [19]. The higher incidence of central hypothyroidism in our study suggested that there was a link between COVID-19 and central hypothyroidism. The exact cause of central hypothyroidism remains unknown. Specific mechanisms may include direct virus damage, hypoxia, systemic inflammation, and ischemia or microthrombus due to hypercoagulability. Despite previous studies showing low levels of ACE2 in the pituitary [20], the detection of
SARS-CoV was established in the autopsied pituitary samples of a SARS patient [21]. Also, the patients with central hypothyroidism had the highest demand for oxygen support in this study, suggesting that severe hypoxia was common in patients with central hypothyroidism. Previous studies have indicated that hypoxia may cause central hypothyroidism [22]. Systemic inflammation may have an impact on pituitary function $[4,23]$. Our results showed that the patients with central hypothyroidism had higher WBC count, neutrophil count, CRP and procalcitonin levels, suggesting a pronounced systemic inflammation in central hypothyroidism. Hypoxia and/or systemic inflammation can lead to hypercoagulability $[24,25]$.

This study found that severe NTIS had a higher proportion of D-Dimer $(>0.5 \mathrm{mg} / \mathrm{L})$ and increased level of fibrinogen, indicating a state of hypercoagulability and even thrombogenesis in central hypothyroidism. Patients with COVID-19 may have ischemia or microthrombus in the pituitary tissue, which affects the pituitary function and leads to central hypothyroidism.

The current study found that the proportion of subclinical hypothyroidism was $7.23 \%$ (17/235) in COVID19 patients. Subclinical hypothyroidism may be caused by the direct destruction of the thyroid by SARS-CoV-2. A previous studies [20] demonstrated an increased expression of ACE2 in the thyroid gland, suggesting that SARS-CoV-2 might access the thyroid gland through ACE2 and cause potential damages. Autopsy results of SARS patients of previous study [26] indicated that

Table 6 Hazard ratios of acute cardiac injury according to different FT3 categories among patients with COVID-19

\begin{tabular}{|c|c|c|c|c|c|c|}
\hline & \multirow{2}{*}{$\begin{array}{l}\text { No of } \\
\text { participants }\end{array}$} & \multirow{2}{*}{$\begin{array}{l}\text { No. } \\
\text { of } \\
\text { cases }\end{array}$} & \multirow{2}{*}{$\begin{array}{l}\text { Person- } \\
\text { days }\end{array}$} & \multicolumn{3}{|c|}{ Hazard ratios ( $95 \%$ confidence intervals) } \\
\hline & & & & Model 1 & Model 2 & Model 3 \\
\hline \multicolumn{7}{|c|}{ Acute cardiac injury } \\
\hline Normal FT3, & 205 & 33 & 6396 & 1.00 & 1.00 & 1.00 \\
\hline Low FT3 ${ }^{\mathrm{b}}$ & 30 & 17 & 916 & $2.39(1.20-4.77)$ & $2.47(1.13-5.37)$ & $3.46(1.90-6.31)$ \\
\hline
\end{tabular}

Model 1 adjusted for age and sex. Model 2 adjusted for age, sex, smoking, systolic blood pressure, fasting glucose, using antihypertensive drugs, and using glucose-lowering drug. Model 3 adjusted for total cholesterol and using lipid-lowering agents. ${ }^{\text {aNormal }}$ FT3 was defined as FT3 within $2.63-5.7$ pmol/L. ${ }^{b}$ Low FT3 was defined as FT3 < 2.63 pmol/L. Abbreviations: COVID-19 coronavirus disease 2019, FT3 Free Triiodothyronine 
thyroid follicular cells and parafollicular cells were damaged, with a large number of follicular epithelial cells exfoliating into the follicle and undergoing apoptosis, with the follicular structure showing distortion, expansion and collapse, no significant calcitonin-positive cells were detected. Our results indicated that the prognosis of subclinical hypothyroidism was better than that of central hypothyroidism, which may suggest that an adequate HPT axis response can improve the prognosis. When the disease affects the thyroid gland, the pituitary gland reactively increases TSH synthesis or secretion to maintain normal levels of T3 and T4. However, when the pituitary reactivity is reduced due to the destruction or inhibition of the pituitary gland, and TSH cannot be compensated to maintain $\mathrm{T} 3$ and $\mathrm{T} 4$ at normal levels, central hypothyroidism ultimately occurs, accompanied by a poor prognosis $[15,27]$. Therefore, the stability of the HPT axis is essential for prognosis.

Our preliminary data suggested that FT3 was a predictor of myocardial injury in COVID-19 patients. Similar to general critical illness, lower circulating T3 levels in acute myocardial infarction patients are associated with more severe clinical symptoms and poorer clinical outcomes [28]. In addition to traditional risk factors, thyroid hormone $(\mathrm{TH})$ metabolic changes are associated with poor prognosis of left ventricular dysfunction in patients with acute decompensated heart failure $[29,30]$. TH receptors exist in myocardial and vascular tissues, and small changes in $\mathrm{TH}$ concentration can affect cardiovascular physiology [31]. Thyroid dysfunction is a potential mechanism for cardiovascular disease, including endothelial dysfunction, changes in blood pressure, myocardial systolic and diastolic dysfunction, and dyslipidemia [31]. Our results showed that the proportion of acute cardiac injury in COVID-19 patients with severe NTIS and mild to moderate NTIS significantly increased, and subclinical hypothyroidism had the highest levels of blood lipids among the four groups. Thus, this study suggested that changes in thyroid hormone levels due to the influence of the HPT axis may be a predictor of myocardial injury.

Critically ill patients with COVID-19 usually require corticosteroids therapy which is known to cause inhibition of TSH secretion [32]. We excluded patients requiring long-term corticosteroids therapy. Although thyroid function was measured in our enrolled patients on the first or second day of admission, 4.3\% (10/235) patients were treated with corticosteroids before thyroid function measurement. We performed statistical analysis for including or excluding them. The patients' exclusion from the analysis did not contribute to a significant change in the results, and thus we chose to retain them in the study.
The current study has certain limitations. First, most of the COVID-19 patients did not undergo a dynamic review of thyroid function, and the dynamic changes of the HPT axis were not shown. Second, reverse triiodothyronine were not measured, therefore partial central hypothyroidism and NTIS were difficult to distinguish. Third, the study sample was not large, and the effect of the intervention on prognosis was not designed in advance, so caution must be attached while interpreting some of the results. Fourth, it is not yet possible to distinguish in which proportions the virus is directly responsible for the dysfunction and in what proportion a subclinical alteration not previously diagnosed can make it susceptible to infection.

\section{Conclusions}

In conclusion, our study showed that the suppression of the HPT axis could be a common complication in COVID-19 patients and an indicator of the severity of prognosis. Compared with the NTF, patients with mild to moderate NTIS and severe NTIS had a worse prognosis and increased risk of myocardial injury. Our study suggests that mild to moderate NTIS and severe NTIS could be associated with the severity of prognosis of COVID-19.

\begin{abstract}
Abbreviations
ARDS: acute respiratory distress syndrome; ACE2: angiotensin-converting enzyme 2; COVID-19: coronavirus disease 2019; Cl: confidence interval; COPD: chronic obstructive pulmonary disease; CRP: c-reactive protein; ESR: erythrocyte sedimentation rate; FT3: Free Triiodothyronine; FT4: Free Thyroxine; HRs: hazard ratios; HPT: hypothalamic-pituitary-thyroid; ICU: intensive care unit; IMV: invasive mechanical ventilation; NTF: normal thyroid function; NTIS: non-thyroidal illness syndrome; SARS-CoV-2: severe acute respiratory syndrome coronavirus 2; TH: thyroid hormone;

TSH: Thyroid-stimulating hormone; WHO: World Health Organization
\end{abstract}

\section{Acknowledgements}

We thank all patients and health provider involved in this study.

\section{Authors' contributions}

J Zheng, LL Chen, TS Zeng, and HQ Li conceived and designed the study; ZH Cui, SH Tian, XY Zhong, KL Qiu and JY Zhang collected the clinical data; J Zheng, NJ Shi and T Chen analyzed the data; J Zheng, ZH Cui and NJ Shi drafted the paper; HQ Li, LL Chen, and TS Zeng reviewed the manuscript and approved its final version. All authors reviewed the manuscript. All authors read and approved the final manuscript.

\section{Funding}

This study was supported in whole or in part by grants from the National Natural Science Foundation of China (grant numbers 81770772 to J.Z. 81974111 to H.Q.L); the Hubei Province Natural Science Foundation (grant number 2019CFB701 to J.Z.); the Hubei Province Health Commission Scientific Research Foundation (grant number 2017 M104 to H.Q.L); the National Key Special Project of Ministry of Science and Technology (grant number 2020YFC0845700 to T.S.Z); and the HUST COVID-19 rapid response call (grant number 2020kfyXGYJ067 to T.S.Z).

\section{Availability of data and materials}

The datasets generated during and analyzed during the current study are available from the corresponding author on reasonable request. 


\section{Declarations}

\section{Ethics approval and consent to participate}

The current study was reviewed and approved by the ethics committee of Tongji Medical College, Huazhong University of Science and Technology, Wuhan, P. R China. Written informed consent was waived by the ethics committee of the Union Hospital, Tongji Medical College, Huazhong University of Science and Technology under the criteria of emerging infectious diseases.

All methods were carried out in accordance with relevant guidelines and regulations.

\section{Consent for publication}

Not applicable.

\section{Competing interests}

The authors declare that they have no conflict of interest.

\section{Author details}

'Department of Endocrinology, Union Hospital, Tongji Medical College, Huazhong University of Science and Technology, Wuhan 430022, China. ${ }^{2}$ Hubei provincial Clinical Research Center for Diabetes and Metabolic Disorders, Wuhan, China.

Received: 23 April 2021 Accepted: 2 November 2021 Published online: 15 November 2021

\section{References}

1. WHO Coronavirus (COVID-19) Dashboard [Internet]. [cited 2021 Sep 12]. https://covid19.who.int

2. Wadman M. How does coronavirus kill? Clinicians trace a ferocious rampage through the body, from brain to toes. Science. [Internet]. 2020. https://doi. org/10.1126/science.abc3208.

3. Leow MK, Kwek DS, Ng AW, Ong K, Kaw GJ, Lee LS. Hypocortisolism in survivors of severe acute respiratory syndrome (SARS). Clin Endocrinol. 2005: 63(2):197-202. https://doi.org/10.1111/j.1365-2265.2005.02325.x.

4. Laghi F, Adiguzel N, Tobin MJ. Endocrinological derangements in COPD. Eur Respir J. 2009;34(4):975-96. https://doi.org/10.1183/09031936.00103708.

5. Fliers $\mathrm{E}$, Bianco $A C$, Langouche $\mathrm{L}$, Boelen $\mathrm{A}$. Thyroid function in critically ill patients. Lancet Diabetes Endocrinol. 2015;3(10):816-25. https://doi.org/10.1 016/S2213-8587(15)00225-9.

6. Karadag F, Ozcan H, Karul AB, Yilmaz M, Cildag O. Correlates of nonthyroidal illness syndrome in chronic obstructive pulmonary disease. Respir Med. 2007;101(7):1439-46. https://doi.org/10.1016/j.rmed.2007.01.016.

7. Lisco G, De Tullio A, Jirillo E, Giagulli VA, De Pergola G, Guastamacchia E, et al. Thyroid and COVID-19: a review on pathophysiological, clinical and organizational aspects. J Endocrinol Investig. 2021;44(9):1801-14. https://doi. org/10.1007/s40618-021-01554-z.

8. WHO. Clinical management of severe acute respiratory infection when novel coronavirus (2019-nCoV) infection is suspected: interim guidance. World Health Organization. [Internet]. 28 January 2020. Available from: https://apps.who.int/iris/handle/10665/330893.

9. Biondi B, Cooper DS. The clinical significance of subclinical thyroid dysfunction Endocr Rev. 2008;29(1):76-131. https://doi.org/10.1210/er.2006-0043.

10. Langouche $L$, Jacobs A, Van den Berghe G. Nonthyroidal illness syndrome across the ages. J Endocr Soc. 2019;3(12):2313-25. https://doi.org/10.1210/ js.2019-00325.

11. Gao C, Wang Y, Gu X, Shen X, Zhou D, Zhou S, et al. Association between cardiac injury and mortality in hospitalized patients infected with avian influenza a (H7N9) virus. Crit Care Med. 2020;48(4):451-8. https://doi.org/10.1 097/CCM.0000000000004207.

12. Thomas ME, Blaine C, Dawnay A, Devonald MA, Ftouh S, Laing C, et al. The definition of acute kidney injury and its use in practice. Kidney Int. 2015; 87(1):62-73. https://doi.org/10.1038/ki.2014.328.

13. Du Y, Tu L, Zhu P, et al. Clinical features of 85 fatal cases of COVID-19 from Wuhan. A retrospective observational study. Am J Respir Crit Care Med. 2020;201(11):1372-9. https://doi.org/10.1164/rccm.202003-05430C.

14. Zhou F, Yu T, Du R, Fan G, Liu Y, Liu Z, et al. Clinical course and risk factors for mortality of adult inpatients with COVID-19 in Wuhan, China: a retrospective cohort study. Lancet. 2020;395(10229):1054-62. https://doi. org/10.1016/S0140-6736(20)30566-3.
15. Scoscia E, Baglioni S, Eslami A, lervasi G, Monti S, Todisco T. Low triiodothyronine (T3) state: a predictor of outcome in respiratory failure? Results of a clinical pilot study. Eur J Endocrinol. 2004;151(5):557-60. https:// doi.org/10.1530/eje.0.1510557.

16. Boonen E, Van den Berghe G. Endocrine responses to critical illness: novel insights and therapeutic implications. J Clin Endocrinol Metab. 2014;99(5): 1569-82. https://doi.org/10.1210/jc.2013-4115

17. Van den Berghe G. Non-thyroidal illness in the ICU: a syndrome with different faces. Thyroid. 2014;24(10):1456-65. https://doi.org/10.1089/thy.2 014.0201

18. den Brinker M, Dumas B, Visser TJ, Hop WC, Hazelzet JA, Festen DA, et al. Thyroid function and outcome in children who survived meningococcal septic shock. Intensive Care Med. 2005;31(7):970-6. https://doi.org/10.1007/ s00134-005-2671-8.

19. Price A, Weetman AP. Screening for central hypothyroidism is unjustified. BMJ. 2001;322(7289):798. https://doi.org/10.1136/bmj.322.7289.798.

20. Li M, Li L, Zhang Y, Wang X. Expression of the SARS-CoV-2 cell receptor gene ACE2 in a wide variety of human tissues. Infect Dis Poverty. 2020;9(1): 45. https://doi.org/10.1186/s40249-020-00662-x.

21. Ding $Y$, He L, Zhang Q, Huang Z, Che X, Hou J, et al. Organ distribution of severe acute respiratory syndrome (SARS) associated coronavirus (SARS-CoV) in SARS patients: implications for pathogenesis and virus transmission pathways. J Pathol. 2004;203(2):622-30. https://doi.org/10.1002/path.1560.

22. Semple PD, Beastall GH, Watson WS, Hume R. Hypothalamic-pituitary dysfunction in respiratory hypoxia. Thorax. 1981;36(8):605-9. https://doi. org/10.1136/thx.36.8.605

23. Wouters EF. Local and systemic inflammation in chronic obstructive pulmonary disease. Proc Am Thorac Soc. 2005;2(1):26-33. https://doi.org/1 0.1513/pats.200408-039MS

24. Gando S. Microvascular thrombosis and multiple organ dysfunction syndrome. Crit Care Med. 2010;38(2 Suppl):S35-42. https://doi.org/10.1097/ CCM.0b013e3181c9e31d

25. Sabit R, Thomas $P$, Shale DJ, Collins $P$, Linnane SJ. The effects of hypoxia on markers of coagulation and systemic inflammation in patients with COPD. Chest. 2010;138(1):47-51. https://doi.org/10.1378/chest.09-2764.

26. Wei L, Sun S, Xu CH, Zhang J, Xu Y, Zhu H, et al. Pathology of the thyroid in severe acute respiratory syndrome. Hum Pathol. 2007;38(1):95-102. https:// doi.org/10.1016/j.humpath.2006.06.011.

27. Higham CE, Johannsson G, Shalet SM. Hypopituitarism. Lancet. 2016; 388(10058):2403-15. https://doi.org/10.1016/S0140-6736(16)30053-8.

28. Friberg L, Drvota V, Bjelak AH, Eggertsen G, Ahnve S. Association between increased levels of reverse triiodothyronine and mortality after acute myocardial infarction. Am J Med. 2001;111(9):699-703. https://doi.org/10.101 6/s0002-9343(01)00980-9.

29. Hayashi T, Hasegawa T, Kanzaki H, Funada A, Amaki M, Takahama H, et al. Subclinical hypothyroidism is an independent predictor of adverse cardiovascular outcomes in patients with acute decompensated heart failure. ESC Heart Failure. 2016:3(3):168-76. https://doi.org/10.1002/ehf2.12084.

30. Rothberger GD, Gadhvi S, Michelakis N, Kumar A, Calixte R, Shapiro LE. Usefulness of serum triiodothyronine (T3) to predict outcomes in patients hospitalized with acute heart failure. Am J Cardiol. 2017;119(4):599-603. https://doi.org/10.1016/j.amjcard.2016.10.045.

31. Razvi S, Jabbar A, Pingitore A, Danzi S, Biondi B, Klein I, et al. Thyroid hormones and cardiovascular function and diseases. J Am Coll Cardiol. 2018;71(16):1781-96. https://doi.org/10.1016/j.jacc.2018.02.045.

32. Kundra P, Burman KD. The effect of medications on thyroid function tests. Med Clin North Am. 2012;96(2):283-95. https://doi.org/10.1016/j.mcna.2012. 02.001

\section{Publisher's Note}

Springer Nature remains neutral with regard to jurisdictional claims in published maps and institutional affiliations. 